\title{
Removal of crystal violet dye from aqueous solutions using rubber (hevea brasillensis) seed shell-based biosorbent
}

\author{
I. A. W. Tan ${ }^{\mathrm{a},}$, , B. H. Hameed ${ }^{\mathrm{b}}$ \\ ${ }^{a}$ Department of Chemical Engineering and Energy Sustainability, Faculty of Engineering, Universiti Malaysia Sarawak, 94300 Kota \\ Samarahan, Sarawak, Malaysia \\ Tel.+60 82 583312; Fax: +60 82 583410; email: awitan@feng.unimas.my \\ ${ }^{b}$ School of Chemical Engineering, University Science Malaysia, Engineering Campus, 14300 Nibong Tebal, Penang, Malaysia
}

Received 6 September 2011; Accepted 20 March 2012

\begin{abstract}
The need of safe and economical methods for the elimination of hazardous dyes from contaminated waters has necessitated research interest towards the production of low-cost adsorbent. The present study aims to investigate the feasibility of rubber seed shell-based biosorbent for removal of crystal violet dye from aqueous solutions. The biosorbent was prepared using sulfuric acid treatment. Fourier transform infrared analysis showed that the main functional groups present on the surface of the biosorbent were aliphatic compounds. Batch adsorption studies were conducted to determine the effects of contact time, initial dye concentration and biosorbent dosage on the uptake of dye at $30^{\circ} \mathrm{C}$. The equilibrium data were analyzed by using Langmuir and Freundlich isotherm models. Equilibrium data fitted well with the Langmuir model, yielding maximum monolayer adsorption capacity of $23.81 \mathrm{mg} / \mathrm{g}$. The kinetic data were found to conform to pseudo-second-order kinetic model with good correlation. Rubber seed shell-based biosorbent was shown to be a promising low-cost material for adsorption of crystal violet dye from aqueous solutions.
\end{abstract}

Keywords: Rubber seed shell; Crystal violet; Biosorption; Equilibrium; Isotherm; Kinetics

${ }^{*}$ Corresponding author. 